\title{
Polymer-modifier for the road bitumen manufacture of the fourth generation
}

\author{
By T.I. Lebedzeva, Y.A. Bulauka
}

Book Topical Issues of Rational Use of Natural Resources 2019

Edition1st Edition

First Published2019

ImprintCRC Press

Pages7

eBook ISBN9781003014638

\section{ABSTRACT}

This study proposes a method for obtaining fourthgeneration road binders, that is, Polymer-modified bitumen. The method is different from the existing ones due to the usage of petrochemical production wastes. Modifying bitumen with petrochemical waste will expand the range of polymer modified bitumens, reduce the involvement of imported additives (such as styrene-butadiene-styrene type polymer), reduce the environmental load andprovide a positive economic effect by using cheaper and more available components compared to industrially used analogs. In addition, obtained polymer modified bitumens, in terms of their basic performance indicators, comply the requirements of modern standards for modified road bitumens, ensuring their reliable operation in the composition of asphalt mixes. 